\title{
Annealing Effect on Microstructure and Superconducting Properties of the V-based Laves Phase Superconducting Wire Synthesized by a RHQ Process
}

\author{
Y. Hishinuma, A. Kikuchi, Y. Iijima, Y. Yoshida, T. Takeuchi, K. Inoue, and A. Nishimura
}

\begin{abstract}
We have studied about annealing effect on V-based Laves phase compound multifilamentary superconducting wire using the Rapidly Heating and Quenching (RHQ) process in order to improve superconducting property. We found that the reaction layer within 10 microns was formed between powder mixture filament and $\mathrm{V}$ matrix after the RHQ process. The transport $J_{c}$ values of samples post-annealed at $600^{\circ} \mathrm{C}$ for 10 hours were increased remarkably compared with as-quenched samples, and then $H_{c 2}$ value calculated by Kramer's formula was increased from $14 \mathrm{~T}$ to $16 \mathrm{~T}$ by additional annealing. In this paper, the post-annealing condition effect on both microstructure and $J_{c}-\mathrm{B}$ property of $\mathrm{V}$-based Laves phase compound superconductor made through RHQ process was investigated.
\end{abstract}

Index Terms-Microstructure, multifilamentary wire, post-annealing, RHQ process, superconducting property, V-based Laves phase compound, $\mathrm{V}_{2}(\mathrm{Hf}, \mathrm{Zr})$.

\section{INTRODUCTION}

$\mathbf{N}$ UCLEAR burning plasma experiments between Deuterium (D) and Tritium (T) reaction are planned on the International Thermonuclear Experimental Reactor (ITER) project to demonstrate for realization of fusion reactors. Generally, a magnetic confinement typed fusion reactor requires both high magnetic field and stable D-T plasma confinement properties in order to maintain the fusion reaction. It is well known that fast neutrons are always formed during fusion reaction between $\mathrm{D}$ and $\mathrm{T}$, and then superconducting magnets of fusion reactor will be irradiated by streaming neutron from many ports which is installed various equipment in fusion device. There is the report which neutron irradiation has been modeled for ITER using Monte Carlo simulation, and it shows

Manuscript received September 20, 2005. This work was supported by the NIFS Program Budgets (NIFS05UCFF006 and NIFS05KKMF001). This work was also supported in part by the Industrial Technology Research Grant Program from New Energy and Industrial Technology Organization (NEDO) of Japan and the Budget for Nuclear Research of the Ministry of Education, Culture, Sports, Science and Technology (MEXT) based on the screening and counseling by the Atomic Energy Commission.

Y. Hishinuma and A. Nishimura are with the National Institute for Fusion Science, Toki, Gifu 509-5292, Japan (e-mail: hishinuma.yoshimitsu@nifs.ac. jp).

A. Kikuchi, Y. Iijima, Y. Yoshida, and T. Takeuchi are with the National Institute for Materials Science, Tsukuba, Ibaraki 305-0047, Japan.

$\mathrm{K}$. Inoue is with the Department of Electrical and Electronic Engineering, University of Tokushima, Tokushima 770-8506, Japan.

Digital Object Identifier 10.1109/TASC.2006.870778 that neutrons of over $1 \mathrm{MeV}$ will come out of a plasma vacuum vessel and reach to the superconducting magnets at the rate of over $10^{11} \mathrm{n} / \mathrm{m}^{2} \mathrm{~s}$ [1]. We think that the streaming of D-T neutron will be generated proportionally for the operation time of fusion reactor, and its fraction will affect to design and total operation schedule including shutdown. Therefore, the prehension of neutronic properties on the superconducting materials for fusion magnet are very important, and the low activation countermeasure of the superconducting magnet by neutron radiation is required as well as high magnetic field properties in order to realize an advanced fusion reactor such as "DEMO" and commercial fusion plants.

In the ITER designs, superconducting coils are fabricated by $\mathrm{Nb}$-based superconducting materials such as $\mathrm{Nb}_{3} \mathrm{Sn}$ and $\mathrm{Nb}-\mathrm{Ti}$. In 1970s and 1980s, some important irradiation tests for superconducting materials were carried out using D-T neutron test facilities and nuclear plants for material testing [2]-[5]. From these reports, $\mathrm{Nb}_{3} \mathrm{Sn}$ superconducting wires synthesized by a bronze method have a peak of the critical current $\left(J_{c}\right)$ property at around the neutron fluence of $10^{22} \mathrm{n} / \mathrm{m}^{2}$ and 14 $\mathrm{MeV}$ pure neutrons irradiation has a tendency to decrease the peak point fluence, and it is assumed that $J_{c}$ property of $\mathrm{Nb}_{3} \mathrm{Sn}$ superconducting wire is depended on neutron energy and total fluence. From the results of neutronics calculation, half-life of niobium by nuclear transition from ${ }^{93} \mathrm{Nb}$ to ${ }^{94} \mathrm{Nb}$ is estimated to be $2.0 \times 10^{4}$ years, and decay period of induced radioactive isotopes to a hands-on level for $\mathrm{Nb}$-based A15 phase compound was evaluated to be about $10^{4}$ years [6]. In the case of advanced fusion reactors after ITER project, it will be hard to use $\mathrm{Nb}$-based superconducting materials in order to construct fusion high field magnet from standpoint of superconductivity and neutronics property.

We will devised the concept of low activation superconductor which specialized in the nuclear fusion application, and tried to develop non $\mathrm{Nb}$ element compound superconductor composed only the low activation elements. V-based Laves phase compounds, $\mathrm{V}_{2}(\mathrm{Hf}, \mathrm{Zr})$, show very attractive superconducting and neutronics properties, superconducting properties of them are maximum $T_{c}=10.1 \mathrm{~K}$ and maximum $H_{c 2}$ above $20 \mathrm{~T}$. And then, V-based Laves phase compound has higher neutron irradiation resistance and the decay period of induced radioactive isotopes to a hands-on level is about 30 years, it is much shorter compared with that of Nb-based A15 phase compound [6]. We 
thought that V-based Laves phase compound superconductor was one of the low activation and high field generation conductors for advanced fusion reactors.

$\mathrm{K}$. Inoue et al. has fabricated $\mathrm{V}_{2}(\mathrm{Hf}, \mathrm{Zr})$ multi-filamentary wires by the diffusion process between $\mathrm{V}$-Hf alloy and $\mathrm{Hf}-\mathrm{Zr}$ alloy, and reported that a rather high temperature of $1100^{\circ} \mathrm{C}$ was required for heat-treatment in order to obtain the high $J_{c}$ property in the high magnetic field [7], [8]. However, the overall $J_{c}$ value of those multifilamentary wires was relatively low, because a lot of $2 \mathrm{nd}$ phases ( $\mathrm{Zr}-\mathrm{Hf}$ based bcc phase) were also formed along the Laves phase. So, we thought that it needed a new process which does not pass through the diffusion reaction in order to fabricate $\mathrm{V}_{2}(\mathrm{Hf}, \mathrm{Zr})$ wires with higher $J_{c}$ values. Recently, we succeeded to fabricate the $\mathrm{V}_{2}(\mathrm{Hf}, \mathrm{Zr})$ Laves phase compound mono-cored tapes and multifilamentary wires by applying the Rapidly heating and Quenching (RHQ) process to the powder-in-tube processed $\mathrm{V}_{2}$ (Hf, $\mathrm{Zr}$ mixture powder/Ta and (Hf, Zr)/V/Ta composite precursors, respectively [9]-[11]. The RHQ process has been successfully developed for advanced $\mathrm{Nb}_{3} \mathrm{Al}$ conductors and is very interesting as a high-temperature short-time heat-treatment, it seems to be able to find as new process in V-based Laves phase compound superconducting wires. In this study, the post-annealing effect on superconductivity and microstructure of Laves phase compound multifilamentary wire synthesized by RHQ process to the $\mathrm{Hf}-\mathrm{Zr}$ metal mixture powder/ $\mathrm{V}$ tube composite in order to optimize heat treatment condition during RHQ process were investigated.

\section{Procedure of Laves Phase Compound MULTIFILAMENTARY WiRE SYNTHESIZED BY RHQ PROCESS}

The multifilamentary Lave phase compound precursor wire was fabricated through the conventional Powder-In Tube (PIT) method. Firstly, high purity metal hafnium (Hf) and zirconium $(\mathrm{Zr})$ powders and vanadium $(\mathrm{V})$ tube having a $10 \mathrm{~mm}$ inner diameter, and a $20 \mathrm{~mm}$ outer diameter and $50 \mathrm{~mm}$ in length were prepared, respectively. The metal $\mathrm{Hf}$ and $\mathrm{Zr}$ powders were adjusted to have equal molar ratio. This powder was well ground by hand, and then wet ball-mill processing was carried out for 3 hours to homogenize the mixed metal powder. In the ball-mill processing, mixed powder was put into zirconia $\left(\mathrm{ZrO}_{2}\right)$ pots with some $\mathrm{ZrO}_{2}$ balls and they were satisfied by the ethyl alcohol to prevent the oxidation of these powder by contamination of the air. After the ball-mill processing, mixed powder was packed into $\mathrm{V}$ tubes. This composite $((\mathrm{Hf}, \mathrm{Zr}) / \mathrm{V})$ was cold-rolled with a grooved roller and the wire drawn a diameter of about $1.20 \mathrm{~mm}$. Intermediate annealing was carried out several times at $900^{\circ} \mathrm{C}$ for 1 hour to soften this composite during this deformation. The (Hf, $\mathrm{Zr}$ )/V composite was cut into short pieces, and they were stacked into a tantalum (Ta) tube having $14 \mathrm{~mm}$ of inner diameter, $20 \mathrm{~mm}$ of outer diameter and $50 \mathrm{~mm}$ of length. The number of stacked (Hf, $\mathrm{Zr}$ )/V composite was 55 pieces. This composite $((\mathrm{Hf}, \mathrm{Zr}) / \mathrm{V} / \mathrm{Ta})$ was cold-rolled with a grooved roller and drawing machine to wire of about $0.754 \mathrm{~mm}$ diameter as well as (Hf, Zr)/V composite. The schematic illustration of fabrication process on the precursor wire and SEM image on cross-section of prepared multifilamentary wire are shown in Fig. 1.

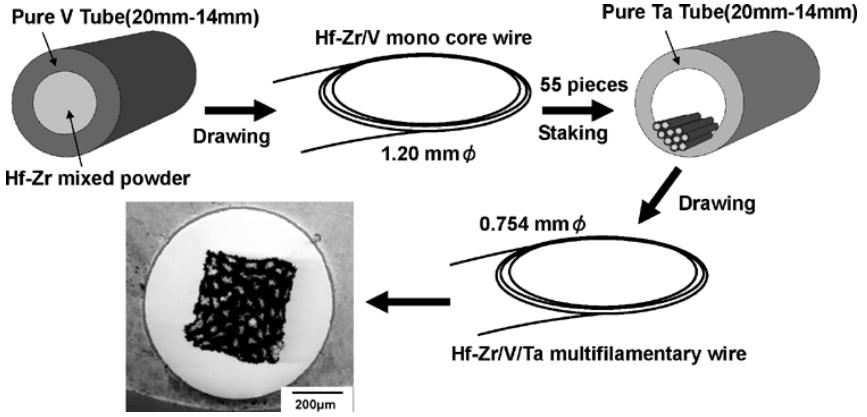

Fig. 1. The schematic illustration of fabrication process on the precursor wire and SEM image on cross-section of prepared multifilamentary wire.

The precursor wire was set into RHQ apparatus, the precursor wire was continuously heated up to the several purpose temperatures with moving at $1.0 \mathrm{~m} / \mathrm{sec}$ of velocity. The precursor wire was heat treated by resistive-heating during $0.1 \mathrm{sec}$, and a dc current transported between an electrode pulley and a molten metal Ga bath. Subsequently, the wire was continuously quenched into the Ga bath at about $40^{\circ} \mathrm{C}$ from above $2200^{\circ} \mathrm{C}$. The coated Ga on the wires was removed by chemical etching in hydrochloric acid after the RHQ treatment. Then, some of the as-RHQ wires were additionally post-annealed at several temperatures from $500^{\circ} \mathrm{C}$ to $900^{\circ} \mathrm{C}$ and time to 100 hours in the vacuum.

$T_{c}$ and $I_{c}$ values of the as-RHQ and post-annealed samples were measured by dc four-probe resistive method. And then, $I_{c}$ measurement was carried out under the several magnetic fields up to $15 \mathrm{~T}$ at $4.2 \mathrm{~K}$. The samples were $\mathrm{Cu}$ plated in order to reduce the contact resistance for the $T_{c}$ and $I_{c}$ measurement. The microstructures of transversely polished cross-sections of the samples were observed using a Scanning Electron Microscope (SEM). Phase identification, mapping of composite elements and quantitative composition analysis of crystal grains were carried out by using an energy dispersive X-ray (EDX) spectrometer.

\section{RESUlTS AND DISCUSSION}

We measured $I_{c}$ values of as-quenched and post-annealed samples under the several magnetic fields at $4.2 \mathrm{~K}$ in order to evaluate the $J_{c}$ properties. The typical $J_{c}-B$ curves of the as quenched and post-annealed samples of $5.86 \mathrm{~J} / \mathrm{mm}^{3}$ are shown in Fig. 2 [11]. The post-annealing conditions are $500^{\circ} \mathrm{C}, 600^{\circ} \mathrm{C}$, $700^{\circ} \mathrm{C}, 900^{\circ} \mathrm{C}$ for 10 hours in vacuum. It was interesting that the Laves phase was already formed by high temperature and short time heat treatment after RHQ process and showed superconductivity. The maximum $J_{c}$ value was estimated to be about $100 \mathrm{~A} / \mathrm{mm}^{2}$ at $4.2 \mathrm{~K}$ and $10 \mathrm{~T}$, for a sample that was post-annealed at $600^{\circ} \mathrm{C} . J_{c}$ dependence of magnetic field on the sample post-annealed at $500^{\circ} \mathrm{C}$ and $600^{\circ} \mathrm{C}$ was remarkably higher than for the as-quenched sample, and the $H_{c 2}$ value of the sample post-annealed at $600^{\circ} \mathrm{C}$ was also improved $2 \mathrm{~T}$ compared to the as-quenched sample from fitting of Kramer's formula. On the other hand, the $J_{c}$ dependence on magnetic field for the sample post-annealed at $900^{\circ} \mathrm{C}$ was lower than for the as-quenched sample as well as its $H_{c 2}$ value. We found that the 


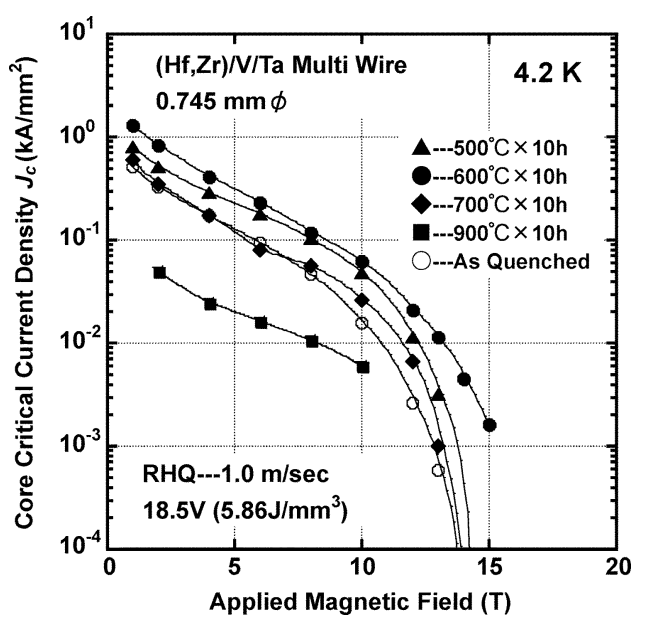

Fig. 2. The typical $J_{c}-B$ curves of the as quenched and post-annealed samples of $5.86 \mathrm{~J} / \mathrm{mm}^{3}$.

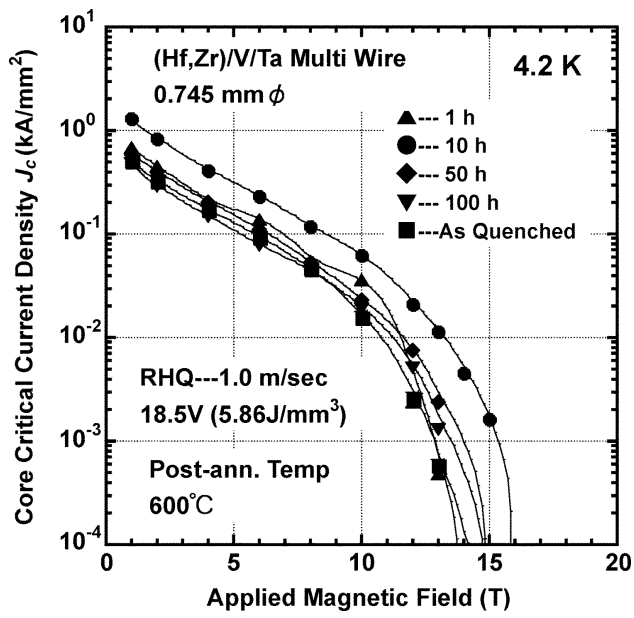

Fig. 3. The typical $J_{c}-B$ curves of the as quenched and post-annealed samples for various annealing time.

optimum post-annealing temperature was $600^{\circ} \mathrm{C}$, this temperature was drastically lower than that of the conventional diffusion processed V-based Laves phase superconductor. This was base on the difference between equilibrium diffusion reaction and nonequilibrium RHQ, and it suggested that post-annealing temperature of RHQ processed Laves phase superconductor was one of the important factors.

In order to study about the optimum post-annealing treatment time, we measured $I_{c}$ values of post-annealed samples for various annealing time under the various magnetic fields at $4.2 \mathrm{~K}$. From the results shown in Fig. 2, we decided that the optimum post-annealing temperature was $600^{\circ} \mathrm{C}$. The typical $J_{c}-B$ curves of the samples of $5.86 \mathrm{~J} / \mathrm{mm}^{3}$ which post-annealed at $600^{\circ} \mathrm{C}$ are shown to Fig. 3. The post-annealing time conditions are $1,10,50$ and 100 hours in vacuum, respectively. $J_{c}$ dependence of magnetic field on the 10 hours annealing sample was remarkably improved compared to that of as-quenched sample. On the other hand, $J_{c}$ dependence of magnetic field on the 50 and 100 hours annealing sample was lowered compared to that of 10 hours annealing sample. The maximum $H_{c 2}$ value of post-annealed sample from fitting of Kramer's formula was 16
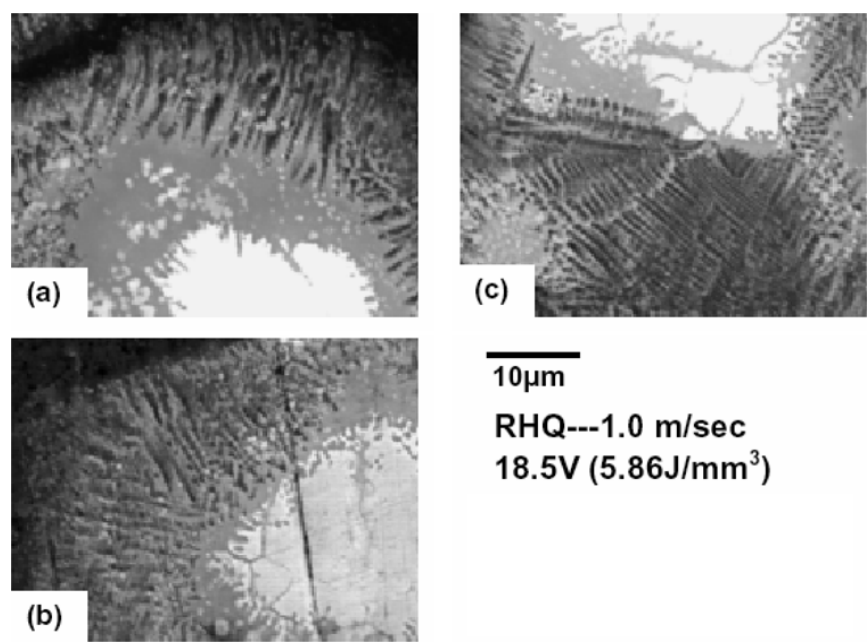

Fig. 4. The typical SEM image of cross-sectional area on the RHQ processed and post-annealed samples. (a) As Quenched (no-Ann); (b) $600^{\circ} \mathrm{C} \times 50 \mathrm{~h}$; (c) $600^{\circ} \mathrm{C} \times 100 \mathrm{~h}$

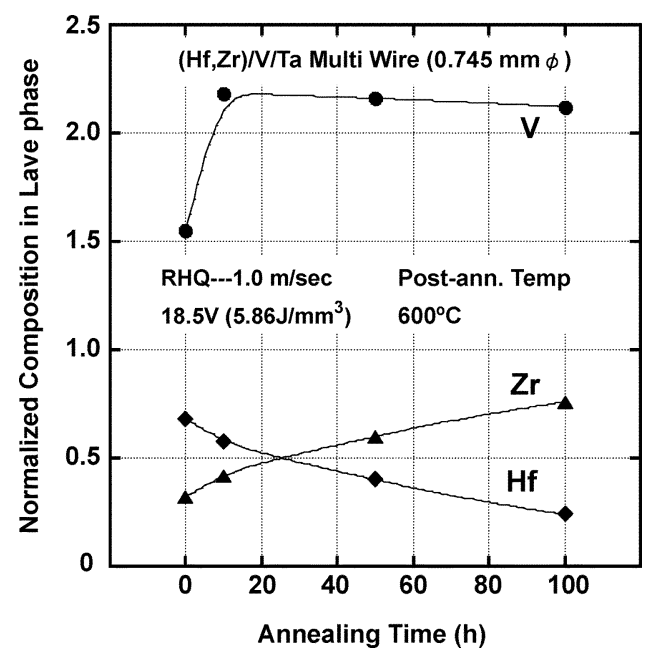

Fig. 5. The average composition of Laves phase in the as-quenched and various post-annealed samples.

$\mathrm{T}$, its value was decreased drastically with extension of post-annealing time. We observed microstructure of cross-sectional area on the various annealing time samples using SEM-EDX. Fig. 4 shows the typical SEM image of cross-sectional area on the RHQ processed samples. Fig. 4(a) is as-quenched samples, (b) and (c) are post-annealed samples. The post-annealed conditions of Figs. 4(b) and 4 (c) are $600^{\circ} \mathrm{C}$ for 50 hours and $600^{\circ} \mathrm{C}$ for 100 hours. We observed that thick reaction layer was formed within 10 microns on the boundary of powder mixture filament and V matrix after the RHQ treatment. In the case of as-quenched samples, Laves and $\beta$ phases ( $\mathrm{Hf}-\mathrm{Zr}$ bcc alloy) were formed in the reaction layer, and that nonreacted metal $\mathrm{Hf}$ and $\mathrm{Zr}$ remained in the $\mathrm{Hf}-\mathrm{Zr}$ powder mixture filaments. And then, it was clear that dendritic grain growth caused from reaction layer with extension of post-annealing time.

Fig. 5 indicates that average composition of Laves phase in the as-quenched and various post-annealed samples based on Fig. 4 . We confirmed that the average composition of Laves phase in as-quenched sample was obtained to be $\mathrm{V}_{1.58}\left(\mathrm{Hf}_{0.68}, \mathrm{Zr}_{0.32}\right)$, 
this composition was significantly deviated to the $\mathrm{V}$-poor side compared with stoichiometry of Laves phase $\left(\mathrm{V}_{2}\left(\mathrm{Hf}, Z_{r}\right)\right)$. This suggests that Laves phase in RHQ process was mainly formed by reaction between metal $\mathrm{V}$ of liquid phase and $\mathrm{Hf}-\mathrm{Zr}$ compound of partial melting phase, and this phase seems to be a nonequilibrium phase. In the case of 10 hours annealed sample, average composition of Laves phase was changed from $\mathrm{V}_{1.58}\left(\mathrm{Hf}_{0.68}, \mathrm{Zr}_{0.32}\right)$ to $\mathrm{V}_{2.18}\left(\mathrm{Hf}_{0.58}, \mathrm{Zr}_{0.42}\right)$, and its composition was almost similar stoichiometry of Laves phase. We thought that $J_{c}$ improvement by post-annealing shown in Figs. 2 and 3 was caused mainly by adjusting composition of Laves phase after RHQ process. In the case of 50 and 100 hours annealed samples, the composition ratio between $\mathrm{Hf}$ and $\mathrm{Zr}$ was changed to Zr-rich and Hf-poor composition relatively compared with that of 10 hours annealed sample. The average compositions were obtained to be $\mathrm{V}_{2.16}\left(\mathrm{Hf}_{0.39}, \mathrm{Zr}_{0.61}\right)$ and $\mathrm{V}_{2.12}\left(\mathrm{Hf}_{0.24} \mathrm{Zr}_{0.76}\right)$, respectively. We found that the composition of Laves phase synthesized by a RHQ process was shifted to Zr-rich side with extension of post-annealing time. On the other hand, there are the reports that the $H_{c 2}$ property of Laves phase compound is lowered with decreasing $\mathrm{Hf}$ content of Laves phase $\mathrm{V}_{2}$ (Hf, $\mathrm{Zr}$ ) [12], [13]. We thought that the lower $J_{c}$-B property on the 50 and 100 hours post-annealed samples shown in Fig. 3 seems to be obtained by the change of the composition caused by the extension of post-annealing time.

\section{CONClusion}

We have successfully fabricated V-based Laves phase compound $\mathrm{V}_{2}(\mathrm{Hf}, \mathrm{Zr})$ multifilamentary wire by applying a rapidly-heating/quenching process to PIT precursor. The composition of Laves phase in as-quenched sample was significantly deviated compared with stoichiometry of Laves phase, and it was changed into stoichiometry by post-annealing. And then, we confirmed that the $J_{c}$ properties of Laves phase was improved by post-annealing and the $J_{c}$ dependence of magnetic field on the post-annealed sample was agreed well with the composition of $\mathrm{V}_{2}(\mathrm{Hf}, \mathrm{Zr})$ Laves phase in post-annealed sample. The optimum post-annealing condition was $600^{\circ} \mathrm{C}$ for 10 hours from the standpoint of microstructure and superconducting properties. This temperature was drastically lower than that of the conventional diffusion processed V-based Laves phase superconductor.

\section{ACKNOWLEDGMENT}

The authors would like to thank Tsukuba Magnet Laboratory of NIMS for allowing the use of high magnetic field magnet facilities for the $I_{c}$ measurement.

\section{REFERENCES}

[1] S. Sato, H. Iida, and T. Nishitani, J. Nucl. Sci. Technol., vol. 39, no. 11, pp. 1237-1246, 2002.

[2] H. W. Weber, "Irradiation damage in superconductors," Adv. Cryog. Eng., vol. 32, pp. 853-860, 1986.

[3] M. W. Guinan, P. A. Hahn, and T. Okada, "Studies of Superconductors and Stabilizers for Fusion Magnets" UCID 21 298, 1988, Summary Report RTNS-II Collaboration Research.

[4] T. Kuroda, K. Katagiri, H. Kodaka, M. Yuyama, H. Wada, K. Inoue, and T. Okada, "Effects of neutron irradiation on the critical temperature and critical current of Nb-tube the critical temperature and critical current of Nb-tube processed $\mathrm{Nb}_{3} \mathrm{Al}$ multifilamentary wires," (in Japanese) $J$. Atomic Energy Soc. Jpn., vol. 37, pp. 94-100, 1995.

[5] P. A. Hahn, H. Hoch, H. W. Weber, R. C. Birtcher, and B. S. Brownahn, "Simulation of fusion reactor conditions for superconducting magnet materials," J. Nucl. Mater., vol. 141-143, pp. 405-409, 1986.

[6] T. Noda, T. Takeuchi, and M. Fujita, "Induced activity of several candidate superconductor materials in a tokamak-type fusion reactor," $J$. Nucl. Mater., vol. 329-333, pt. 2, pp. 1590-1593, 2004.

[7] K. Inoue, T. Kuroda, and K. Tachikawa, "Superconducting properties of $\mathrm{V}_{2}(\mathrm{Hf}, \mathrm{Zr}$ ) Laves phase multifilamentary wires," J. Nucl. Mater., vol. 133-134, pp. 815-818, 1985.

[8] K. Inoue, H. Wada, T. Kuroda, and K. Tachikawa, "Stress effects on superconducting properties of the composite processed $\mathrm{V}_{2}(\mathrm{Hf}, \mathrm{Zr})$,", Appl. Phys. Lett., vol. 38, pp. 939-941, 1981.

[9] Y. Hishinuma, A. Kikuchi, Y. Iijima, Y. Yoshida, A. Nishimura, T. Takeuchi, and K. Inoue, "Microstructure and superconductivity of $\mathrm{V}$-based Laves phase compound superconductor synthesized rapidlyheating/quenching process," J. Nucl. Mater., vol. 329-333, pt. 2, pp. 1580-1584, 2004.

[10] Y. Hishinuma, A. Kikuchi, Y. Iijima, Y. Yoshida, T. Takeuchi, A. Nishimura, and K. Inoue, "Fabrication of V-based Laves phase compound superconductor through rapidly-heating/quenching process," Supercond. Sci. Technol., vol. 17, pp. 1031-1036, 2004.

[11] - , "Fabrication of $\mathrm{V}$-based laves phase compound multifilamentary wires by applying a rapidly-heating/quenching process to PIT precursors and using V tube," IEEE Trans. Appl. Supercond., vol. 15, no. 2, pp. 3536-3539, 2005.

[12] K. Inoue and K. Tachikawa, IEEE Pub., no. 72, pp. 415-418, 1972, CHO682-5-TABSC, (Proc. 1972 Appl. Supercond. Conf.).

[13] K. Inoue, "The Research on Superconducting Characteristic and Wire Deformation of V-based Laves Phase Compound," Ph.D. dissertation, Dept. Materials. Eng., Tokyo Univ., Tokyo, 1987. 